Pampallona, S., Bollini, P., Tibaldi, G., et al (2002) Patient adherence in the treatment of depression. British Journal of Psychiatry, 180, 104-109.

Peveler, R., George, C., Kinmonth, A.-L., et al (1999) Effect of antidepressant drug counselling and information leaflets on adherence to drug treatment in primary care: randomised controlled trial. BMJ, 319, 612-615.

A. C. M. Vergouwen, A. Bakker Department of Psychiatry, Sint Lucas Andreas Hospital, PO Box 9243, 1006 AE Amsterdam, The Netherlands

Authors' reply: The point raised by $\mathrm{Mr}$ Lawton-Smith is of the utmost importance, but we found no published randomised studies that considered patients' perspectives as an entry point for interventions to improve compliance. To fill this gap, our group has recently completed a qualitative study involving patients, families and therapists to identify their concerns with adherence and to design effective interventions. We agree with $\mathrm{Mr}$ Lawton-Smith that much remains to be done to adapt research methodologies and clinical practices to the needs expressed by people with mental illnesses.

Vergouwen \& Bakker incorrectly attribute our statement, 'the important relationship between adherence and outcome of treatment has been evaluated only in one study' to randomised interventions, when it referred to descriptive studies, both in the Results and Discussion sections. Out of the 14 randomised interventions we reviewed, only five reported data on response which could be extracted. In addition, the design applied by the five studies made it impossible in our review to explore the relationship between intervention and response.

S. Pampallona, P. Bollini forMed Statistics for Medicine, Evolène, Switzerland

G. Tibaldi, B. Kupelnick, C. Munizza Centro Studi e Ricerche in Psichiatria, Piazza del Donatore di Sangue 3, I0I54 Torino, Italy

\section{Cost of somatisation}

Steven Reid and colleagues (2002) have introduced a welcome addition to the UK literature on somatisation with their clear demonstration that unexplained symptoms may be associated with significant use of secondary care health care resources. They emphasise a key point, repeatedly demonstrated, that somatisation is expensive for health care systems. However, their report may tell us more about the behaviour of doctors and health care systems than the behaviour of patients.

By selecting only frequently attending patients, they have controlled for the most important variable in cost of out-patient care, the cost of out-patient attendances. Their own figures show that the costs of attendances represented $74.5 \%$ and $85.9 \%$ of total out-patient care costs for somatising and non-somatising frequent attenders, respectively. They refer to a major US study (Escobar et al, 1987) which demonstrated very high rates of use of secondary care medical resources among patients with separately diagnosed somatisation. By controlling for attendance in their study design, they have almost certainly diluted the apparent impact of somatisation on secondary care use in this sample - an impact they rightly emphasise.

For a significant number of these frequently attending patients, negative investigations were followed by a repeat of the cycle. Those with repeatedly unexplained symptoms were designated 'somatisers' by the authors, implying a disorder in the patient. The medical response to these symptoms may in fact be as important in explaining continued resource use. The reasons why doctors behave in these characteristic ways are less than clear our inability to live with uncertainty, our unwillingness to go with our judgement. Recent attempts to emphasise the importance of the issue are welcome (Bass et al, 2001), but until we more clearly understand doctors' behaviour when faced with these patients, we may remain simply counting the considerable costs.

Bass, C., Peveler, R. \& House, A. (200I) Somatoform disorders: severe psychiatric illnesses neglected by psychiatrists. British Journal of Psychiatry, 179, 11-14.

Escobar, J. I., Golding, J. M., Hough, R. L., et al (1987) Somatization in the community: relationship to disability and use of services. American Journal of Public Health, 77 $837-840$.

Reid, S., Wessely, S., Crayford, T., et al (2002) Frequent attenders with medically unexplained symptoms: service use and costs in secondary care. British Journal of Psychiatry, 180, 248-253.

B. Sheehan Oxford University, Department of Psychiatry, Warneford Hospital, Headington, Oxford OX3 7JX, UK

\section{Recruitment of psychiatrists}

Brockington \& Mumford (2002) and Storer (2002) target a topic of major concern in their thoughtful papers on recruitment to psychiatry. I was particularly interested in the comments on 'Background factors affecting the recruitment of psychiatrists' (pp. 308-309). In 1998 an article of mine was published concerning a smallscale survey of the characteristics of consultant forensic psychiatrists (Prins, 1998). As part of this survey, I asked 37 consultants (of whom 30 replied) what had led them to take up (a) psychiatry and (b) forensic psychiatry. (Other questions concerned attractions and difficulties in the latter field.) I am concerned here only to detail some of the responses to question (a). I discovered that some clinicians have indicated background influences publicly. For example, Professor Pamela Taylor has stated that, 'Two of the more powerful influences in my personal background were chronic, deteriorating neurological illness in the family, and the Church' (Taylor, 1997: p. 20). Professor Robert Bluglass has written with considerable candour and humour about the persistence of his early efforts to enter medical school (Bluglass, 1996: p. 96). Less publicly, some of the respondents referred to similar experiences - for example, serious illness or exposure to the suffering of others, particularly within the family or as a result of experiences in the armed forces. Several came from backgrounds in medicine; interestingly, for some, school influences seemed very important. Overall, a dominant theme that emerged was of an interest in people rather than in 'illness' per se. However, a few appeared to have entered psychiatry almost by default (the word is not used here in any pejorative sense): 'I was too clumsy with my hands for surgery'; 'I was not physically suitable'. Mine was a very small-scale survey but happily confirmed by Brockington \& Mumford's findings; namely, that a decision was taken at a fairly early age to enter medicine, with a later decision to enter psychiatry. These seemed to be determined largely by a feeling of lack of satisfaction with the less personal and holistic aspects of other specialist medical practice. Since schools and other early experiences seem to be quite influential, it may be that more attention should be paid to this aspect than has been the case hitherto. The interesting 
reasons why my respondents chose forensic psychiatry may be found at pp. 144-146 of my paper.

Bluglass, R. (1996) Valedictory address: Free use of unexpired time: my criminal career. Criminal Behaviour and Mental Health, 6, 95-106.
Brockington, I. \& Mumford, D. (2002) Recruitment into psychiatry. British Journal of Psychiatry, I80, 307-312

Prins, H. (1998) Characteristics of consultant forensic psychiatrists (a modest survey). Journal of Forensic Psychiatry, 9, 139-149.

Storer, D. (2002) Recruiting and retaining psychiatrists. British Journal of Psychiatry, 180, 296-297.
Taylor, P. J. (1997) Damage, disease and danger. Criminal Behaviour and Mental Health, $\mathbf{7}$, 19-49.

H. Prins | Home Close Road, Houghton on the Hill, Leicester LE7 9GT, UK

\section{One hundred years ago}

\section{The keeping of lunatics in unlicensed houses}

ON Saturday, Oct. 4th, Sarah Roach was charged at the North London Police-court with receiving certain lunatics in an unlicensed house and was fined $£ 20$ on one charge and $£ 5$ on another, with five guineas costs. The credit of putting an end to a disgraceful scandal belongs entirely to our contemporary Truth. In the issue of Truth of May 29th there appeared a striking article entitled "Nursing Home or Hell," a record of horrors written with a forcible precision that could not fail to arrest attention. As a result of this article the Commissioners in Lunacy communicated with the editor of Truth, who at once gave them all the evidence which he had collected as to the condition of the Alexandra Nursing Home, the "hell" in question, and of the inmates thereof. On June 20th two of the Commissioners in Lunacy, Dr. E. M. Cooke and Mr. Charles Bagot, visited the "Home," and after what they saw the law was set in motion. It moved with its usual dignified pace, so that Sarah Roach did not find herself in a police-court until Oct. 4th, and having got there she escaped, it seems to us, with a light penalty. The serious thing about the case is that there were in all 11 patients in the "Home"; of these nine showed signs of mental derangement but two only were bad enough to be certified as lunatics. In the cases of these two proceedings were taken and legal penalties were exacted, but if no patient had been certifiable the law would have been powerless against Sarah Roach, except, possibly, as regards some sanitary defaults. This should not be. As Truth has remarked in commenting upon the case later, it is only too common for families to be burdened with aged or afflicted relatives of whom they are glad to be rid by boarding them out at the cheapest rate. We have no doubt that the Alexandra Nursing Home is not the only retreat of the kind where helpless senility falls in a terrible environment to a miserable grave.

\section{REFERENCE}

Lancet, 18 October 1902, p. 1069

Researched by Henry Rollin, Emeritus Consultant Psychiatrist, Horton Hospital, Epsom, Surrey 